\title{
CT scan in severe diffuse head injury: physiological and clinical correlations
}

\author{
EVELYN TEASDALE, ERICO CARDOSO,* SAMUEL GALBRAITH, \\ GRAHAM TEASDALE \\ From the Institute of Neurological Sciences, Southern General Hospital, Glasgow, Scotland
}

SUMMARY CT scan findings, clinical features and intracranial pressure were studied in patients with severe diffuse head injury. Compression of the 3rd ventricle and basal cisterns closely correlated with an intracranial pressure $>20 \mathrm{mmHg}$, with clinical signs of midbrain dysfunction and worse prognosis. These CT scan findings can indicate whether intracranial pressure monitoring is appropriate.

CT scanning is very accurate in the diagnosis of cerebral compression caused by intracranial clot or other focal traumatic space occupying lesions. Severe diffuse brain damage, in the absence of a clot, can also cause increased intracranial pressure (ICP), but this affects only a minority of patients, even of those in coma. In patients with diffuse head injury, attempts to relate CT scan findings, such as the appearance of small or "slit like" lateral ventricles, to a raised ICP have given conflicting results. ${ }^{1-4}$ We report the correlation of a CT scan appearance suggestive of compression of the CSF pathways at the tentorial hiatus and 3rd ventricle with the level of ICP and the clinical state of a series of patients with severe diffuse brain damage.

\section{Patients and methods}

Thirty seven patients, each diagnosed as a severe diffuse head injury were studied. All were in coma at the time of the scan and none had a lucid interval between injury and investigation. The majority $(90 \%)$ were scanned within 12 hours of injury. The presence of intraventricular or diffuse subarachnoid blood did not preclude inclusion in the study; however, a midline shift of $>5 \mathrm{~mm}$ did. The ICP was monitored by intraventricular catheter inserted immediately following the scan and a modal ICP during the next 24 hours was determined. A pressure of $>20 \mathrm{mmHg}$ was regarded as moderately elevated. The CT scans were reviewed by a neuroradiologist unaware of the level of the ICP or the

${ }^{*}$ Present address: 1081 Carling Avenue, Suite 703, Ottawa K1Y 4G2, Ontario, Canada.

Address for reprint requests: DE Teasdale, Institute of Neurological Science, Govan Road, Glasgow G51 4TF, UK.

Received 8 November 1983. Accepted 5 January 1984 clinical state of the patient. The features noted were the presence or absence of the CSF spaces corresponding to the 3rd ventricle and basal cisterns (in particular the ambient or perimesencephalic cistern).

\section{Results}

The patients Glasgow Coma Score ${ }^{5}$ and pupillary reactions at the time of the scan were recorded as an index of the initial severity of the brain damage and outcome was assessed in survivors 6 months later. ${ }^{6}$ The average age of the patients was 17 years (range 2-58) and at the time of admission Glasgow Coma Scores were recorded as 3-5 in 14 patients and 6-8 in 23 patients. Non-reacting pupils were found in eight. Twenty patients died or became vegetative, six recovered but were dependant and 11 made a moderate to good recovery.

The CT scan appearances identified three groups of patients. (A) 18 patients in whom both the 3rd ventricle and basal cisterns were identified as normal on the scan, (B) nine patients in whom the CT scan showed that one of the spaces was obliterated; in eight patients this was the 3rd ventricle and in two of these the basal cisterns were seen only because they contained blood. Two other patients with basal subarachnoid blood had patent 3 rd ventricles and so were included in group A. The third group, (C), contained 10 patients in whom neither the 3 rd ventricle nor the basal cisterns could be detected (fig. 1).

Twenty three patients had a modal pressure of 20 $\mathrm{mmHg}$ or less, and 14 had a pressure ranging from 21 to $80 \mathrm{mmHg}$. Figure 2 shows that there was a highly significant relationship (Mann Whitney 2 Sample Rank Test for medians $p<0 \cdot 01$ ), between 600 

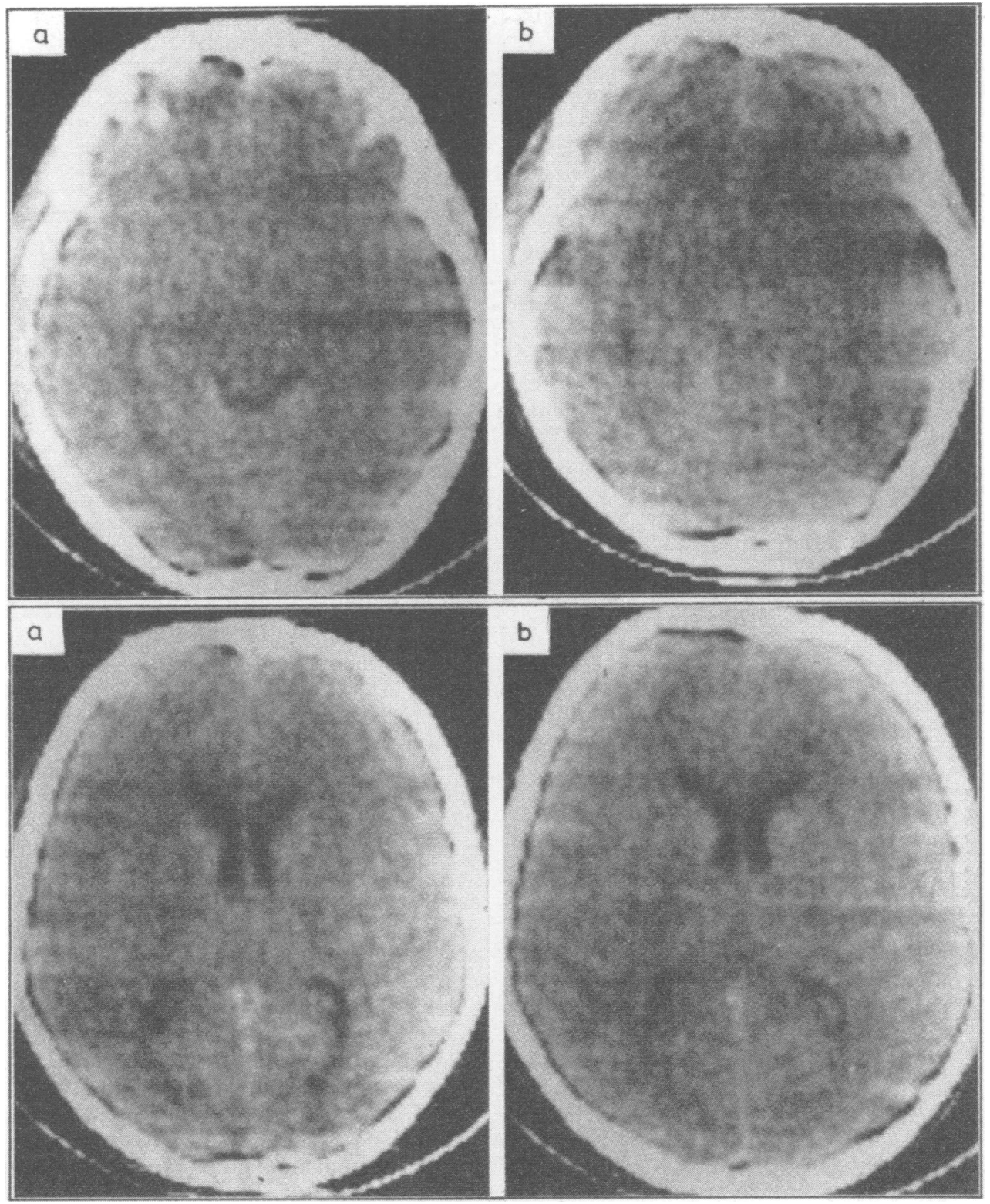

Fig 1 (a) CT scan showing normal lateral ventricles, absent IIIrd ventricle but present quadrigeminal cistern-ICP $20 \mathrm{mmHg}$. (b) ICP increased to $35 \mathrm{mmHg}$-repeat CT scan showing persistently normal lateral ventricles but now absent cisterns as well as IIIrd ventricle.

the appearances of the 3 rd ventricle and basal cisterns and the level of ICP. The mean ICP in patients in group $A$ whose scan showed both CSF spaces was $11.5 \pm 5.8 \mathrm{mmHg}$; in group $B$ patients, with one absent, it was $35 \pm 26 \cdot 1 \mathrm{mmHg}$ and in group $\mathrm{C}$, those with both absent $35 \cdot 2 \pm 12 \cdot 2 \mathrm{mmHg}$. Of the four patients with blood in the subarachnoid spaces, the two whose 3rd ventricles were seen had an ICP of $<20 \mathrm{mmHg}$ whereas those with an absent 3 rd ventricle had an ICP of 80 and $70 \mathrm{mmHg}$. All patients whose ICP was $>20 \mathrm{mmHg}$ had at least one CSF space obliterated. On the other hand none of the 18 
patients whose 3 rd ventricle and basal cisterns were both present had an ICP of $>20 \mathrm{mmHg}$.

Twenty four patients had ICP recordings continued for more than 24 hours. Of 14 patients with ICP below $20 \mathrm{mmHg}$ only two later rose of $>20$ $\mathrm{mmHg}$, and of 10 patients with ICP $>20 \mathrm{mmHg}$ the pressure fell in four but remained elevated in six.

Clinical correlations are summarised in tables 1 and 2. Failure to detect the 3rd ventricle or cisterns was more common in patients in extremely deep coma (coma score $<5$ ) and was associated with a worse outcome (table 1). The association between cistern appearances and outcome held even when patients were divided into different severities of brain damage on the basis of Coma Score. There was also a correlation between the CT scan finding and pupillary reaction (table 2). Of the eight patients with non-reacting pupils, in only one were the basal cisterns present on the scan. On the other hand, obliteration of the cisterns was not always associated with non-reacting pupils, and $60 \%$ of these patients had one or more pupil reacting.

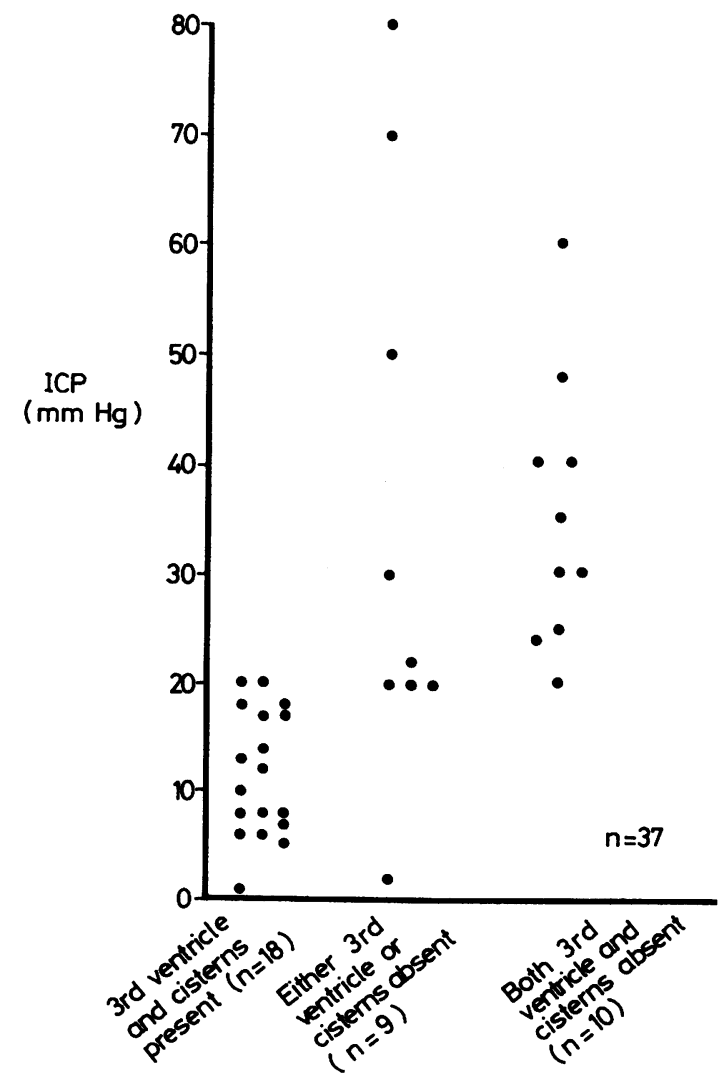

Fig 2 Relationship between modal ICP and the CT scan appearances of CSF spaces.
Table 1 Relationship between CSF spaces, GCS and outcome

\begin{tabular}{|c|c|c|c|c|}
\hline $\begin{array}{l}\text { Glasgow Coma } \\
\text { Score }\end{array}$ & $\begin{array}{l}\text { Cistern/ } \\
\text { IIIrd Ventricle }\end{array}$ & $\begin{array}{l}\text { Dead/ } \\
\text { vegetative }\end{array}$ & Severe & $\begin{array}{l}\text { Moderate/ } \\
\text { good }\end{array}$ \\
\hline $\begin{array}{l}6-8 \\
3-5\end{array}$ & $\begin{array}{l}\text { Absent } \\
\text { Present } \\
\text { Absent } \\
\text { Present }\end{array}$ & $\begin{array}{r}3 \\
3 \\
10 \\
3\end{array}$ & $\begin{array}{l}2 \\
2 \\
1\end{array}$ & $\begin{array}{l}3 \\
8 \\
1 \\
1\end{array}$ \\
\hline
\end{tabular}

Table 2 Relationship between CSF spaces and pupillary response

\begin{tabular}{lll}
\hline $\begin{array}{l}\text { Pupillary } \\
\text { response }\end{array}$ & $\begin{array}{l}\text { Cisterns } \\
\text { present }\end{array}$ & $\begin{array}{l}\text { Cisterns } \\
\text { absent }\end{array}$ \\
\hline $\begin{array}{l}\text { or both reacting } \\
\text { Neither reacting }\end{array}$ & 17 & 12 \\
\hline
\end{tabular}

\section{Discussion}

The mechanisms involved in severe diffuse head injury are complex but our findings show that damage that is sufficiently severe to produce moderately increased ICP also produces CT scan appearances of obliteration of the 3rd ventricle and the cisterns at the tentorium. This demonstration of brain swelling and of intracranial shift in life correlates well with findings in fatal cases. Adams and Graham ${ }^{7}$ reported a series of head injured patients whose ICP had been measured before death, and showed that when the ICP had been $>40 \mathrm{mmHg}$, the brain at necropsy showed evidence of focal necrosis in the parahippocampal gyrus. They attributed this to pressure from the edge of the tentorium, an event likely to be associated with local obliteration of the CSF pathways. Our observation that of eight patients with absence of pupillary reaction, seven had absent cisterns is also in accordance with this view.

In patients with apparently similar severities of brain damage as judged by their Glasgow Coma Score, cisternal obliteration indicated a worse prognosis. It may therefore add to prognostic information. Obliteration of the cisterns appeared to precede severe midbrain dysfunction, thus preserved pupillary responses were present in 12 of 19 patients with this CT sign.

Obliteration of the 3rd ventricle appeared to be an earlier event than cisternal compression and a more sensitive CT index of increased ICP. The only patient with obliteration of the 3rd ventricle and an ICP of $<20 \mathrm{mmHg}$ had a small paraventricular thalamic haematoma causing only local distortion. In two other patients the discrepancy between the absent 3rd ventricle and detectable cisterns was because the latter were filled with blood and it may be significant that these two patients had the highest 
ICP observed in this study.

The major buffer against events tending to increase ICP is a reduction in CSF volume. Obstruction to CSF flow is likely to accompany the appearance on CT of obliteration of the basal cisterns and 3 rd ventricle. This will work against compensation by causing dilatation of the lateral ventricles and so in itself contribute to the development of significantly raised ICP. This may explain the close correlation observed in this study between CT signs of CSF pathway obliteration and an increased ICP. It may also explain why previous attempts to relate raised ICP to CT estimates of the size of the lateral ventricles ${ }^{1-4}$ have failed. Thus the amount of CSF in the ventricles and their size is determined by the balance between compression due to brain swelling and distension as a result of the flow of CSF being impeded by cisternal and 3rd ventricle obliteration.

The demonstration that an abnormality of intracranial anatomy detectable by CT can predict the physiological disorder of raised ICP may be clinically useful. In the absence of a haematoma only a minority of head injured patients have raised ICP. If the CT scan clearly shows normal CSF pathways, especially the 3rd ventricle and basal cisterns, the patients ICP is very likely to be normal and unlikely to increase significantly in future. Such a patient is unlikely either to require or to benefit from measures aimed at reducing ICP and the value of monitoring ICP may be outweighed by its disadvantages. Patients with absent cisterns are extremely likely to have raised ICP but only $40 \%$ have clinical signs of tentorial herniation and severe midbrain dysfunction. Patients with absent cisterns and preserved midbrain function may benefit from ICP monitoring. However, this may depend upon the devising of methods for identifying the precise cause(s) of the brain swelling so that specific and effective steps can be taken to limit their progression and to prevent the onset of brain stem compression.

\section{References}

${ }^{1}$ Haar F, Sadhu VK, Gildenberg P, Sampson J. Can computed tomographic scan findings predict intracranial pressure in closed head injury patients? Neurosurgery 1980; 7:290-1 (abstr).

${ }^{2}$ Holliday III PO, Kelly D, Ball M. Normal computed tomograms in acute head injury: Correlation of intracranial pressure, ventricular size, and outcome. Neurosurgery 1982;10, 1:25-8.

${ }^{3}$ Sadhu VK, Sampson J, Haar F, Pinto R, Handel S. Correlation between computed tomography and intracranial pressure monitoring in acute head trauma patients. Radiology 1979;133:507-9

${ }^{4}$ Tabaddor K, Danziger A, Wisoff H. Estimation of intracranial pressure by CT scan in closed head trauma. Surg Neurol 1982;18, 3:212-5.

s Teasdale G, Jennett B. Assessment of coma and impaired consciousness. Lancet 1974;ii:81-84.

- Jennett B, Bond M. Assessment of outcome after severe brain damage. Lancet 1975;i:480.

${ }^{7}$ Adams JH and Graham DI. The relationship between ventricular fluid pressure and the neuropathology of raised intracranial pressure. Neuropathol Appl Neurobiol 1976;2:323-32. 